\begin{tabular}{|c|c|}
\hline Citation & $\begin{array}{l}\text { M. Wang, W. Leterme, G. Chaffey, J. Beerten, D. Van Hertem, } \\
\text { Protection and Pole Rebalancing for Pole-to-ground Faults in } \\
\text { Symmetrical Monopolar HVDC Grids } \\
\text { Proc. 15th IET International Conference on AC and DC Power Transmission } \\
\text { (ACDC 2019), Coventry, UK, 5-7 Feb. 2019, } 6 \text { pages. }\end{array}$ \\
\hline Archived version & $\begin{array}{l}\text { C } 2019 \text { IET. This paper is a postprint of a paper submitted to and accepted for } \\
\text { publication in Proc. IET International Conference on AC and DC Power } \\
\text { Transmission } 2019 \text { and is subject to Institution of Engineering and Technology } \\
\text { Copyright. The copy of record is available at IET Digital Library. }\end{array}$ \\
\hline \multicolumn{2}{|l|}{ Published version } \\
\hline Author contact & $\begin{array}{l}\text { Mian Wang mian.wang@kuleuven.be } \\
\text { tel: }+ \text { 32 } 16374300\end{array}$ \\
\hline
\end{tabular}

(article begins on next page) 


\title{
Protection and Pole Voltage Rebalancing for Pole-to-ground Faults in Symmetrical Monopolar HVDC Grids
}

\author{
M. Wang*, W. Leterme*, G. Chaffey*, J. Beerten*, D. Van Hertem* \\ ${ }^{*}$ Department of Electrical Engineering (ESAT), Division Electa \& Energyville, University of Leuven (KU Leuven) \\ Thor Park 8310, 3600 Genk, Belgium Email: mian.wang@kuleuven.be
}

Keywords: Pole rebalancing, dynamic braking system, zigzag transformer, primary protection, backup protection, protection sequence

\begin{abstract}
Pole rebalancing in symmetrical monopolar HVDC grids is necessary to remove pole imbalances resulting from pole-toground faults. For selective protection employing DC circuit breakers, pole rebalancing considering backup protection operation in case of breaker failure has until now not been studied. This paper proposes fault clearing and post-fault restoration sequences including pole rebalancing to deal with DC-side faults, considering both primary and backup protection operations. The performance of the proposed sequences and the impact of the key breaker parameters on pole rebalancing are investigated in a four-terminal test system using PSCAD/EMTDC.
\end{abstract}

\section{Introduction}

Voltage source converter (VSC) based high voltage direct current (HVDC) grids provide an efficient means to interconnect large amounts of renewable energy and facilitate an integrated European market [1]. Currently, the majority of VSC HVDC systems are built as point-to-point connection with a symmetrical monopolar configuration. Interconnecting such links could be a cost effective solution to build meshed HVDC grids. HVDC grid protection is one of the technical challenges that needs to be addressed to realize meshed HVDC grids. One promising protection methodology uses selective protection algorithms and DC circuit breakers (DCCB).

Pole-to-ground faults in symmetrical monopolar HVDC grids impose different requirements on the HVDC grid protection system compared with DC faults in asymmetrical monopolar or bipolar HVDC grids [2]. Without countermeasures after fault clearing, pole-to-ground faults in symmetrical monopolar systems result in persistent overvoltage on the healthy pole, and consequently, pole rebalancing is a necessary step to restore the system. Furthermore, in cable-based HVDC grids pole-topole faults are considered very rare, whereas the majority of the faults are pole-to-ground faults [3]. This gives rise to opportunities for alternative HVDC grid protection design; different from present AC protection. Therefore, DCCBs might not be required to interrupt pole-to-pole faults, thus the required current interruption and energy absorption capabilities can be reduced for DCCB only designed for handling pole-to-ground faults [3]. In such protection systems, alternative equipment is required to handle pole-to-pole faults, for instance, AC circuit breakers for interruption and bypass switches to protect the DCCB in case they are not designed to withstand the fault currents. Therefore, the dimension of the DCCB are considered only for pole-to-ground faults in this paper.

In the literature, pole rebalancing methods are mainly studied in HVDC grids without DCCBs. These methods use a dynamic braking system (DBS) or an AC side grounding permitting pole imbalance removal through $\mathrm{DC}$ ground or $\mathrm{AC}$ zero sequence currents $[4,5]$. In the case of HVDC grid protection with DCCBs, [6] has shown the possibility of using DBSes for pole rebalancing, and [7] has given detailed analysis on using both DBSes and AC side groundings for pole rebalancing to coordinate with DCCB operation. However, to the best of our knowledge, pole rebalancing considering backup protection operation in case of DCCB failure has not been studied. DCCB failure will trigger backup protection operation, which leads to multiple DCCBs opening and reclosing. It is thus crucial to design protection sequences including pole rebalancing to be coordinated with both primary and backup protection operations.

The aim of this paper is to investigate behaviour of the converter station in case of primary and backup protection, and propose complete protection sequences including pole rebalancing to deal with both primary and backup protection operations. The proposed protection sequences are validated in a four-terminal test network using a detailed equivalent converter model. Furthermore, the impact of the DCCB opening time, reclosing waiting time and the line inductor on the requirements of DCCBs and pole rebalancing equipment are analysed. Recommendations on choosing DCCB main parameters in combination with pole rebalancing equipment are given as conclusions.

\section{Pole Rebalancing Principle and Equipment}

This section briefly reviews pole rebalancing principles and equipment described in detail in [7].

In a symmetrical monopolar configuration, a discharge path for the healthy pole is necessary in order to rebalance the pole voltages after a pole-to-ground fault. Using the zero sequence equivalent model given in [7], the discharge path for the healthy pole using a DBS or AC side grounding is illustrated in Fig. 1 (b), only one of these devices will be used at a given time. FCU stands for fault clearing unit, including a high-speed switch (HSS), a DCCB and a DC line inductor. During fault clearing, the switches $S_{1}$ and $S_{2}$ of the pole rebalancing equipment 
are in open position to prevent current flowing through the DBS or the AC side grounding. After fault clearing, $S_{1}$ or $S_{2}$ is closed in order that the healthy pole can discharge through the DBS or the $\mathrm{AC}$ side grounding.
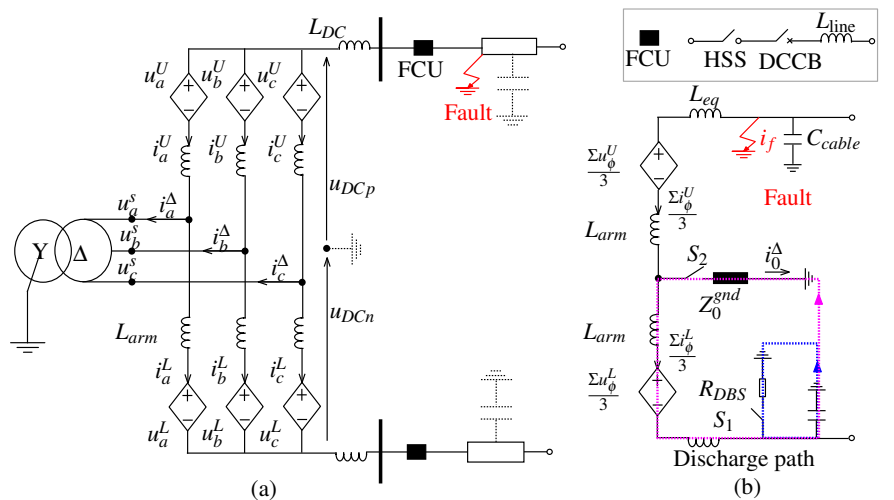

Fig. 1: Modular multilevel converter (MMC) station with symmetrical monopolar configuration: (a) Circuit diagram (b) Zero sequence equivalent circuit with a DBS or AC side grounding $\left(L_{e q}=L_{D C}+L_{\text {line }}\right)$.

In the remainder of this paper, a surge arrester based DBS and a zig-zag transformer (Fig. 2) are used as examples to investigate the complete protection sequence, since alternative DBS and $\mathrm{AC}$ side grounding circuits are expected to have similar performance [7].

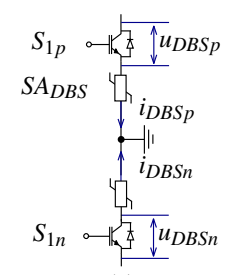

(a)

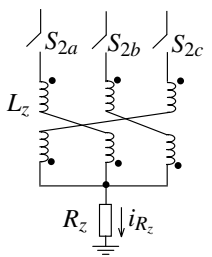

(b)
Fig. 2: Examples of pole rebalancing equipment: (a) Surge arrester based DBS (b) Zig-zag transformer.

\section{Protection Sequences Including Backup Protection Operation}

\subsection{Converter response during backup operation}

In a fully selective protection strategy, all lines and the converter terminal are equipped with DCCBs as shown in Fig. 3. In case a DCCB fails to interrupt the faulted line, all adjacent DCCBs connected to the same DC bus are ordered to open. As a result, the converter remains isolated until the DCCBs in the adjacent lines are reclosed. To achieve fast post-fault restoration, the isolated converter is required to remain connected to the AC-side and maintain a constant DC voltage close to $1 \mathrm{pu}$, so that the converter can be timely reconnected with the HVDC grid. One possible way is to use DC voltage control until reconnecting to the DC grid. For instance, if the converter is under active power or droop control mode (P/P-Vdc control), it can momentarily switch to DC voltage control and switch back to the pre-fault control mode after reconnection.

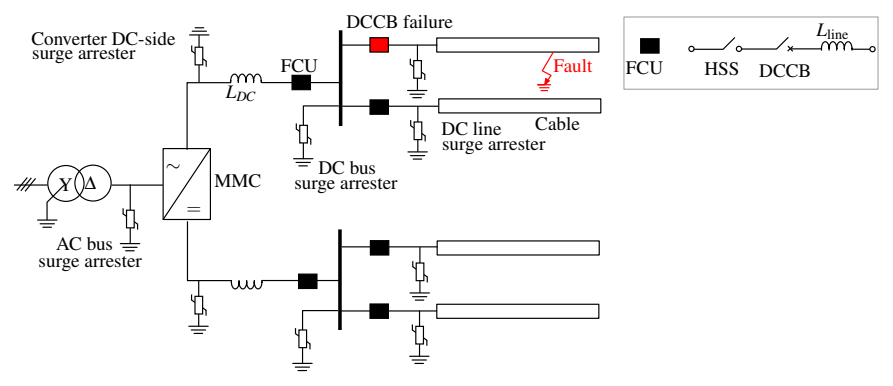

Fig. 3: MMC station adopting a fully selective strategy using DCCBs.

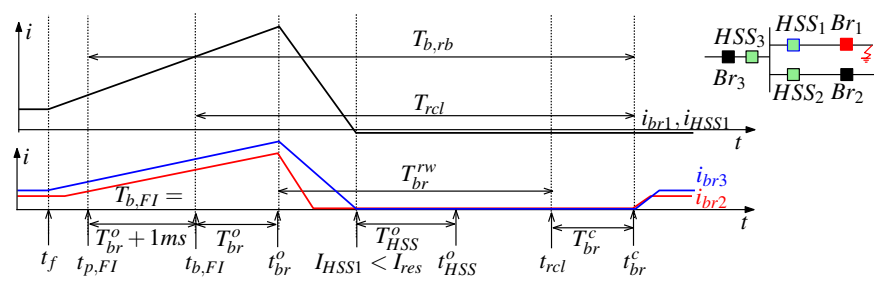

Fig. 4: Breaker opening and reclosing sequence.

\subsection{Protection Sequence}

The simplest way to avoid fault current contribution from the pole rebalancing equipment prior to backup protection operation is to estimate the longest delay caused by the backup operation and only operate the pole rebalancing equipment after this estimated delay. Given the breaker operation sequence shown in Fig. 4, the fixed delay $\left(T_{b, r b}\right)$ should be at least

$$
T_{b, r b}=T_{b, F I}+T_{b r}^{o}+T_{b r}^{r w}+T_{b r}^{c}+\text { margin }
$$

where $T_{b, F I}, T_{b r}^{o}, T_{b r}^{r w}$ and $T_{b r}^{c}$ are the time delays for breaker failure detection, breaker opening, breaker reclosing waiting and breaker closing, respectively.

An alternative way is to use signals communicated by the intelligent electronic devices (IEDs) to operate the pole rebalancing equipment, so that the instant for beginning pole rebalancing can be tuned for every fault scenario (Fig. 5). Output signals from the local DC line IEDs, fault detection (FD), fault identification (FI) and breaker failure detection $(\mathrm{BF})$ are used to determine the instant to operate the pole rebalancing equipment. Depending on these three signals, the pole rebalancing equipment can take three different actions:

- Remote: the converter station is considered as a remote station if all IEDs only detect but not identify a DC fault. In such situation, the converter is electrically far away from the DC fault location, thus not significantly impacted by the fault. The pole rebalancing equipment is operated after the presumed breaker opening delay $\left(T_{b r}^{o}\right)$.

- Primary operation: one of the DC line protection IEDs identified the fault is on the line and breaker failures are not detected after the presumed breaker failure detection delay $\left(T_{b, F I}\right)$. The pole rebalancing equipment is operated after the breaker failure detection delay.

- Backup operation: Breaker failure is detected and the adjacent DCCBs are reclosed. The pole rebalancing equipment is operated after reclosing the adjacent DCCBs.

$\diamond$ After the backup DCCBs interrupt the fault current, the HSS of the failed DCCB is ordered to open once the current is lower than the residual current $\left(I_{H S S}<I_{\text {res }}\right)$. 


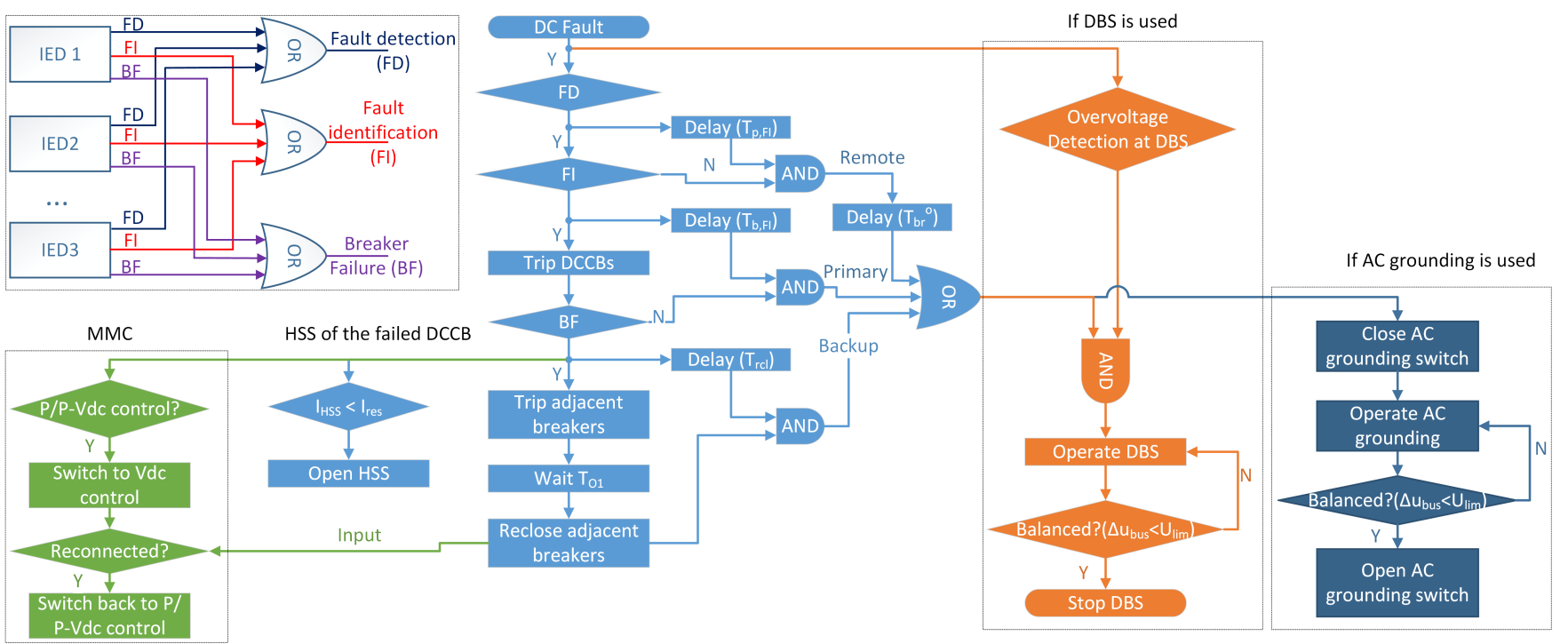

Fig. 5: Detailed protection sequence for operating DBSes or AC side groundings using local IED communication.

$\diamond$ The breaker failure signal is communicated to the converter control and protection, so that necessary control actions are taken to maintain the MMC terminal DC voltage close to $1 \mathrm{pu}$.

Once the pole voltages are rebalanced within the set limits $\left(\Delta u_{\text {bus }}<U_{\text {lim }}\right)$, the operation of the pole rebalancing equipment is stopped.

\section{Test System}

A four-terminal system, shown in Fig. 6, is used to validate the proposed protection sequences. The converters are modelled with a Type 4 detailed equivalent circuit model as specified in [8], where individual submodule switching states and capacitor voltages are represented. The main parameters of the converter station are listed in Table 1 . The DBSes and AC groundings are implemented at the two onshore stations: MMC1 and MMC3. For each study, only one of the options, DBS or AC grounding, is activated. Considering a hybrid DCCB, the breaker opening time $\left(T_{b r}^{o}\right)$ and the series inductor $\left(L_{\text {line }}\right)$ are assumed to be $2 \mathrm{~ms}$ and $50 \mathrm{mH}$, the breaker reclosing waiting time $\left(T_{b r}^{r w}\right)$ is assumed to be $40 \mathrm{~ms}$ unless stated otherwise [9]. A solid pole-to-ground fault $\left(f_{1}\right)$ is applied at the terminal of the positive pole of link $L_{13}$.

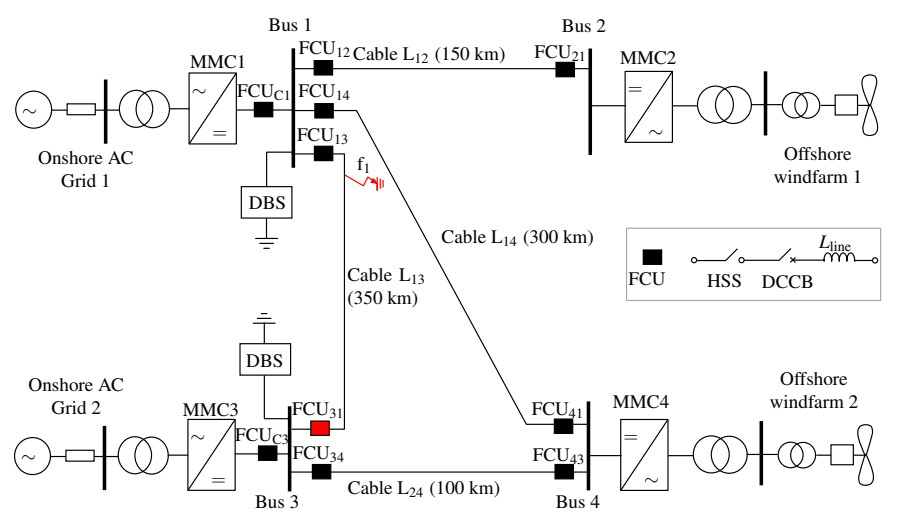

Fig. 6: Four-terminal symmetrical monopolar HVDC grid test system.
Table 1: Converter and grid parameters

\begin{tabular}{lll}
\hline Parameters $($ Symbol) & Value & Unit \\
\hline Rated power & 1265 & {$[\mathrm{MVA}]$} \\
Rated active power & 1200 & {$[\mathrm{MW}]$} \\
Rated DC voltages & \pm 320 & {$[\mathrm{kV}]$} \\
Rated AC voltages & $400 / 333$ & {$[\mathrm{kV}]$} \\
Transformer leakage impedance $(\mu)$ & 0.18 & $\mathrm{pu}$ \\
\hline Arm inductance $\left(L_{\text {arm }}\right)$ & 42 & {$[\mathrm{mH}]$} \\
DC smoothing reactor $\left(L_{D C}\right)$ & 10 & {$[\mathrm{mH}]$} \\
Line inductor $\left(L_{\text {line }}\right)$ & $10-100$ & {$[\mathrm{mH}]$} \\
Submodule capacitance & 8.8 & {$[\mathrm{mF}]$} \\
Submodule number/arm & 400 & \\
\hline
\end{tabular}

\subsection{Pole rebalancing equipment}

The parameters of the pole rebalancing equipment and their controls are chosen based on [7]. The most important ones are briefly recapitulated below. The reference voltage of the surge arrester, $\mathrm{SA}_{\mathrm{DBS}}$ of the DBS is chosen to have a switching impulse protection level of $1.2 \mathrm{pu}$. The voltage imbalance hysteresis band is 1.05 to $1.1 \mathrm{pu}$ to control the DBS operation. The zig-zag transformer is dimensioned same as [7], with a grounding resistor of $300 \Omega$.

\subsection{DC line protection}

In each IED located at each end of a line, primary protection and breaker failure backup are implemented. This study considers local measurements based protection algorithms, which have a detection time of few hundreds of microseconds and few ms for primary and backup protection, respectively [10-12]. The fault detection of the primary protection is emulated using a fixed time delay of $0.5 \mathrm{~ms}$ after the fault initiated travelling wave arrives at the IED position. The breaker failure detection is emulated using a time delay of breaker opening time with an additional $1 \mathrm{~ms}$ margin. Once breaker failure is detected, the HSS of the failed breaker is ordered to open when the current in the HSS is less than the specified residual current (e.g. $10 \mathrm{~A}$ ). 


\subsection{Overvoltage protection surge arresters}

Both AC-and DC-side surge arresters (Fig. 3) are implemented to provide overvoltage protection. The AC-side surge arrester considered in this study is the AC bus surge arrester located at the converter side, since the converter side of the transformer is expected to experience overvoltages due to the superimposed DC voltage imbalance during a pole-to-ground fault. Additionally, DC line, DC bus and converter DC-side surge arresters are implemented with a protection level of $1.8 \mathrm{pu}$. All surge arresters take the U-I-characteristic given in [13].

\section{Case Studies}

\subsection{Primary protection with and without communication}

Without communication from the local IEDs, the fixed delay $T_{b, r b}$ is set to be $50 \mathrm{~ms}$, considering $T_{b r}^{o}=2 \mathrm{~ms}$ and $T_{b r}^{r w}=40 \mathrm{~ms}$.

The pole rebalancing time and required DC surge arrester energy absorption capabilities are lower for the protection sequence with local communication compared to the one without communication (Fig. 7). In this analysis, the pole rebalancing time is defined as the interval from fault inception to the instant when the pole voltage returns within the normal range ([0.95 - 1.05] pu). The pole rebalancing time and the required DC side surge arrester energy is $120 \mathrm{~ms}$ and $0.2 \mathrm{MJ}$ with communication, which are significantly less than $206 \mathrm{~ms}$ and $1.5 \mathrm{MJ}$ without using communication.

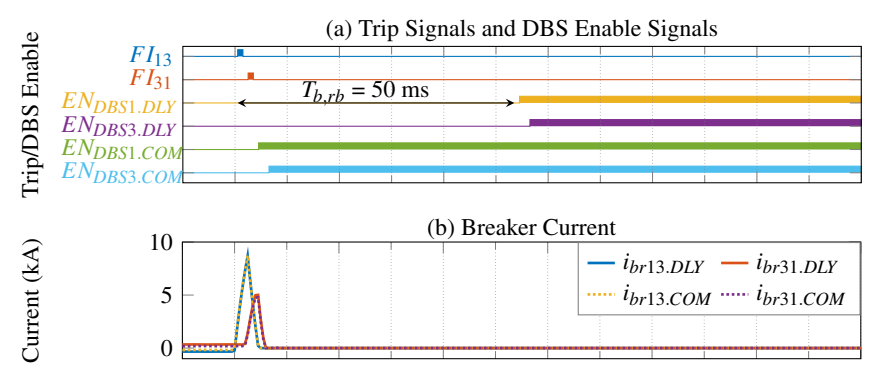

(c) DC Bus1 Voltages

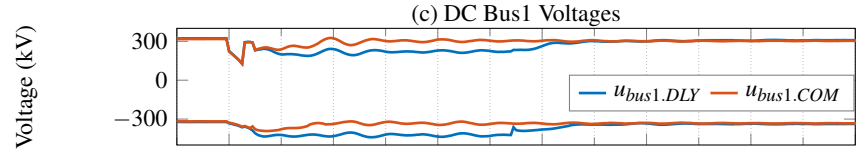

(d) Negative Pole DBS Current

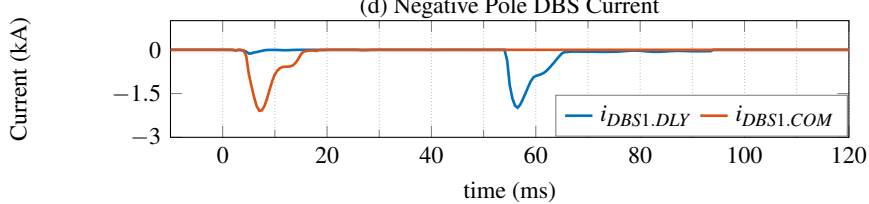

Fig. 7: Primary protection: pole rebalancing performance using DBSes, $T_{b r}^{o}=2 \mathrm{~ms}, T_{b r}^{r w}=40 \mathrm{~ms}$ and $T_{b, r b}=50 \mathrm{~ms}$

\subsection{Backup protection}

The protection sequence with communication shown in Fig. 5 is implemented in the four-terminal test system, assuming $B r_{31}$ failure. The simulation waveforms are shown in Fig. 8 and Fig. 9 for using DBSes and zig-zag transformers, respectively. In both cases, the pole rebalancing equipment at MMC1 is ordered to operate once $B r_{13}$ is opened. At MMC3, upon breaker failure detection, $\mathrm{Br}_{\mathrm{C} 3}$ and $\mathrm{Br}_{34}$ are ordered to open. Subsequently, the HSS of $\mathrm{Br}_{31}$ is opened, once $I_{H S S 31}<10 \mathrm{~A}$. $B r_{C 3}$ and $B r_{34}$ are then ordered to reclose after the assumed breaker reclosing waiting time of $40 \mathrm{~ms}$. The DBS or zig-zag transformer at MMC3 only operates once the backup DCCBs are reclosed.

Both DBS and zig-zag transformer can achieve pole rebalancing in the case of backup protection operation, with each offering different advantages and disadvantages. The main advantages of the DBSes are the short rebalancing time and low arm overvoltages. The rebalancing time is $133 \mathrm{~ms}$ using DBSes, which is approximately $75 \mathrm{~ms}$ faster than using zig-zag transformers. As shown in Fig. 1, due to the discharge of the healthy pole through the zig-zag transformer, the DC offset of the lower arm voltages are higher, which results in overvoltages on the lower arms (Fig. 9 (e)). On the contrary, the benefit of using the zigzag transformer is a lower required energy absorption capability. The total energy absorbed is $1.7 \mathrm{MJ}$ and $13 \mathrm{MJ}$ in zig-zag transformers and DBSes, respectively.

(a) Trip Signals and Breaker Status

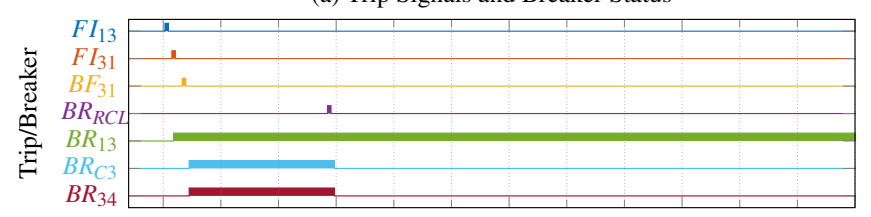

(b) Breaker and MMC Current
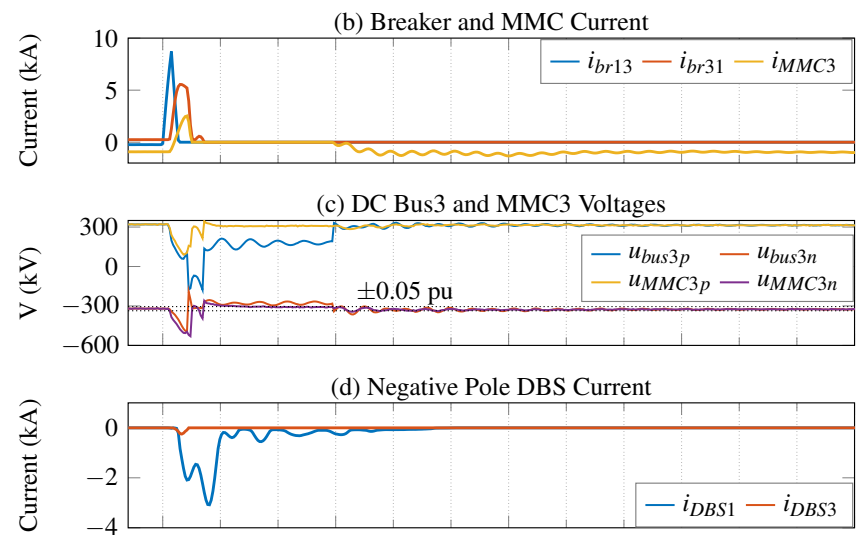

(e) Sum of Submodule Capacitor Voltages (MMC1)

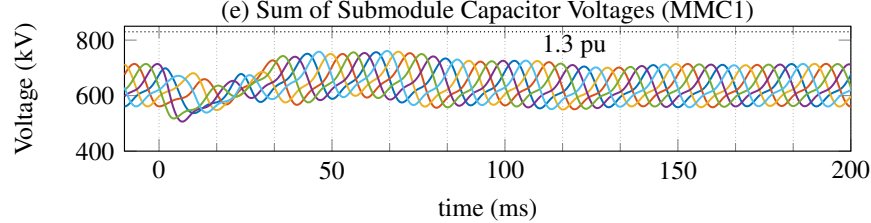

Fig. 8: Backup protection: pole rebalancing performance using DBSes, $T_{b r}^{o}=2 \mathrm{~ms}, T_{b r}^{r w}=40 \mathrm{~ms}$.

\subsection{Impact of breaker parameters on pole rebalancing during backup protection}

This section investigates the impact of $T_{b r}^{o}, T_{b r}^{r w}$ and $L_{\text {line }}$ on the breaking current requirement, pole rebalancing speed and required energy absorption capabilities of DCCBs, DC bus/line surge arresters and the pole rebalancing equipment in the HVDC grid. The following analysis examines protection sequences using communication from local IEDs. The same fault and breaker failure conditions are assumed in this section.

\subsubsection{Breaker opening time}

The breaker opening time is varied from $2 \mathrm{~ms}$ to $20 \mathrm{~ms}$ with a 1 $\mathrm{ms}$ interval and the line inductor is fixed at $50 \mathrm{mH}$. 


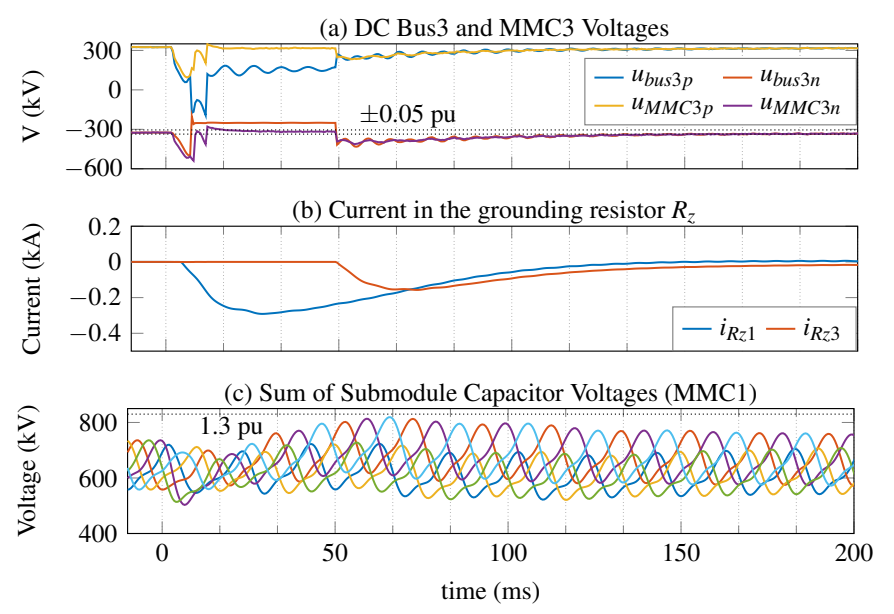

Fig. 9: Backup protection: pole rebalancing performance using zig-zag transformers, $T_{b r}^{o}=2 \mathrm{~ms}, T_{b r}^{r w}=40 \mathrm{~ms}$.

The breaker current and energy do not linearly change with the breaker opening time (Fig. 10 (a)-(d)). A short breaker opening time results in a high required breaking current and energy absorption capability on the primary breaker. The influence of the breaker opening time on the required energy absorption capabilities of the backup DCCBs is insignificant.

A long breaker opening time results in high energy dissipation in the DBSes (Fig. $10(\mathrm{e})$ ), as the DBS at the primary protection station (MMC1) absorbs energy through the fault before the backup DCCBs at MMC3 open. As a result, the required energy absorption capability of the line backup breaker $B_{34}$ is slightly higher than using zig-zag transformers.

There is a trade-off between the primary breaker requirement and the required total energy absorption capability of the HVDC grid. Using a fast DCCB results in a high requirement on the DCCB; however, using a slow DCCB requires the pole rebalancing equipment and DC side surge arresters to be capable of dissipating a large amount of energy.

The pole rebalancing time increases sightly with longer breaker opening times. Pole rebalancing with DBSes is much faster than with zig-zag transformers using the studied dimensions.

\subsubsection{Breaker reclosing waiting time}

The breaker reclosing waiting time is varied from $20 \mathrm{~ms}$ to $100 \mathrm{~ms}$, considering practical cooling time of the semiconductors in a hybrid DCCB [9] and constraints on pole rebalancing time.

The breaker reclosing waiting time only slightly prolongs the pole rebalancing time, and the influence on the requirement on pole rebalancing equipment and DC side surge arresters is negligible (Fig. 11).

The maximum of the sum submodule capacitor voltage per arm increases with longer breaker opening time and reclosing waiting time (Fig. 12). This implies that the choice of DCCBs is limited when using $\mathrm{AC}$ side groundings for pole rebalancing if the converter submodules are designed to withstand certain overvoltage levels. For instance, if the converter submodules are dimensioned to withstand 1.3 pu overvoltage [14], it is necessary to use fast DCCBs with a short reclosing waiting time (Fig. 12.)

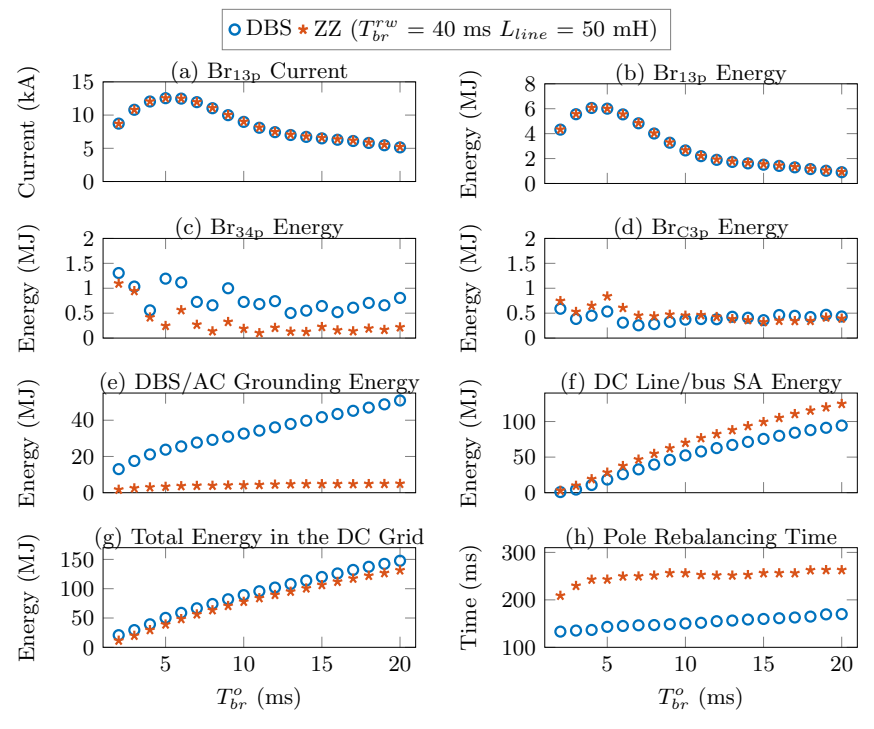

Fig. 10: Backup protection: impact of breaker opening time on pole rebalancing, $T_{b r}^{r w}=40 \mathrm{~ms}, L_{\text {line }}=50 \mathrm{mH}$, DBS: using DBSes, ZZ: using zig-zag transformers, subscript $_{\mathrm{p}}$ : positive pole.

○DBS $(2 \mathrm{~ms}) * \mathrm{ZZ}(2 \mathrm{~ms}) \Delta \mathrm{DBS}(20 \mathrm{~ms})+\mathrm{ZZ}(20 \mathrm{~ms})$
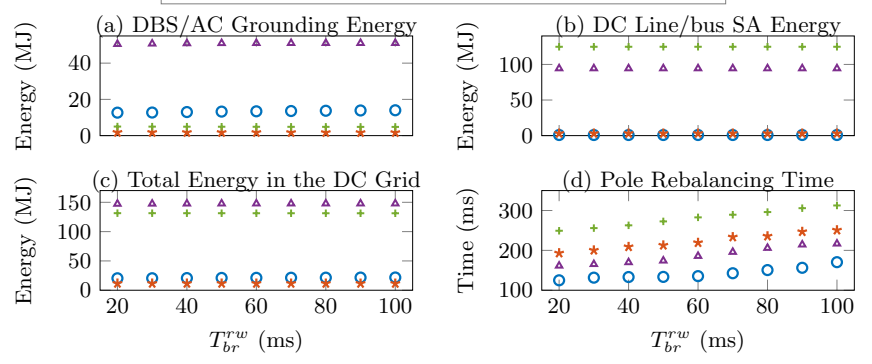

Fig. 11: Backup protection: impact of breaker reclosing waiting time on pole rebalancing, $T_{b r}^{o}=2,20 \mathrm{~ms}, L_{\text {line }}=$ $50 \mathrm{mH}$, DBS: using DBSes, ZZ: using zig-zag transformers.

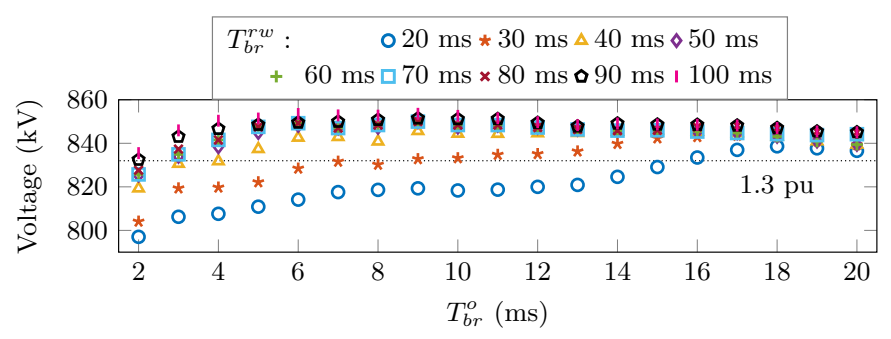

Fig. 12: Backup protection: impact of breaker opening time and breaker reclosing waiting time on the maximum of the sum submodule capacitor voltage per arm at $\mathrm{MMC1}$ when using zig-zag transformers, $L_{\text {line }}=$ $50 \mathrm{mH}$.

\subsubsection{Line inductor}

The line inductors are varied from $10 \mathrm{mH}$ to $200 \mathrm{mH}$ with a 10 $\mathrm{mH}$ interval. Breaker opening time of $2 \mathrm{~ms}$ and $20 \mathrm{~ms}$, and a breaker reclosing waiting time of $40 \mathrm{~ms}$ are considered.

Both primary and backup breaker requirements are influenced by the line inductor size (Fig. 13 (a) - (d)). For the primary breaker, it is more beneficial to use relatively large inductor with fast DCCBs to reduce the breaking current and energy requirements; however, smaller inductor size is preferable if slow 
DCCBs are used. For the backup DCCBs, using smaller line inductor size is preferable. The line inductor size has insignificant impact on the pole rebalancing equipment and DC side surge arrester dimensions (Fig. 13 (f)).
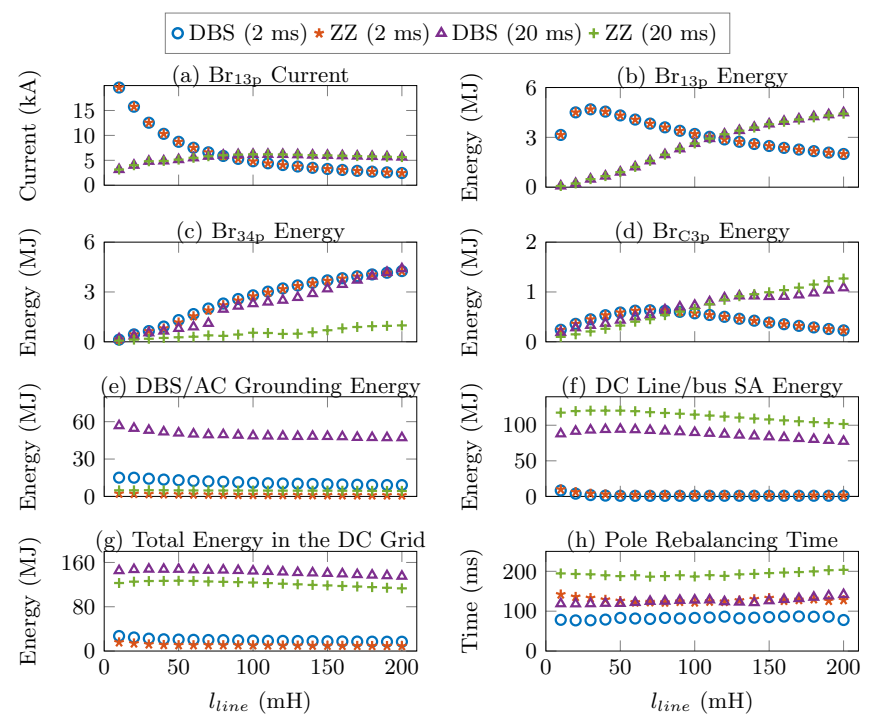

Fig. 13: Backup protection: impact of line inductor on pole rebalancing, $T_{b r}^{o}=2,20 \mathrm{~ms}, T_{b r}^{r w}=40 \mathrm{~ms}$, DBS: using DBSes, ZZ: using zig-zag transformers.

\section{Conclusion}

The proposed protection sequences are able to coordinate fault clearing and pole rebalancing under both primary and backup protection operations. The communication-based protection sequence provides faster voltage restoration compared to the one without communication, thereby favouring the pole rebalancing performance.

Both DBSes and AC side groundings are capable of rebalancing the pole voltages under backup protection operation. The main advantages of DBSes are fast rebalancing speed and reduced overvoltage on the converter submodules. Although the required energy absorption capability of the $\mathrm{AC}$ side groundings is much less compared to the DBSes, the pole rebalancing speed is slower in case of backup protection operation. When using AC side groundings for post-fault voltage rebalancing, the converter submodule overvoltage capability and the DCCB speed have to be carefully considered to respect the converter submodule overvoltage constraints. Among the three investigated key DCCB parameters, the breaker opening time was found to be most influential on the required current interruption and absorption capability of the DCCB, and the required energy absorption capabilities of the pole rebalancing equipment and DC side surge arresters.

\section{Acknowledgements}

This work has received funding from the European Union's Horizon 2020 PROMOTioN project (Progress on Meshed HVDC Offshore Transmission Networks) under grant agreement No. 691714. The work of Jef Beerten is funded by a research grant of the Research Foundation-Flanders (FWO).

\section{References}

[1] D. Van Hertem, O. Gomis-Bellmunt, and J. Liang, HVDC Grids: For Offshore and Supergrid of the Future, ser. IEEE Press Series on Power Engineering. Hoboken, New Jersey, USA.: Wiley, 2016.

[2] W. Leterme, P. Tielens, S. De Boeck, and D. Van Hertem, "Overview of grounding and configuration options for meshed HVDC grids," IEEE Trans. Power Del., vol. 29, no. 6, pp. 2467-2475, Dec. 2014.

[3] PROMOTioN WP 4, "D4.1 Definition of test cases and functional requirements for DC grid protection methodologies,” Tech. Rep., Feb. 2017.

[4] G. Chaffey and T. C. Green, "Low speed protection methodology for a symmetrical monopolar HVDC network," in Proc. IET ACDC 2017, Manchester, UK, 1416, Feb. 2017, 6 pages.

[5] L. Tang, "Control and Protection of Multi-Terminal DC Transmission Systems Based on Voltage-Source Converters," Ph.D. dissertation, McGill University, Montreal, Quebec, Canada, 2003.

[6] P. Mitra, J. Hanning, J. Kohlstrom, T. Larsson, and J. Danielsson, "DC grid system behavior: A real-time case study," in 2015 IEEE PES GM, Denver, U.S., 2630 , July 2015, 5 pages.

[7] M. Wang, W. Leterme, G. Chaffey, J. Beerten, and D. Van Hertem, "Pole Rebalancing Methods for Pole-toground Faults in Symmetrical Monopolar HVDC Grids," IEEE Trans. Power Del., early online access.

[8] Cigré working group B4.57, "Guide for the Development of Models for HVDC Converters in a HVDC Grid," Paris, France, Tech. Rep., Dec. 2014.

[9] PROMOTioN Work Package 9, "Deliverable 6.9 Standard DC CB model verification plan and RTDS models," Tech. Rep., Jan. 2018.

[10] W. Leterme, J. Beerten, and D. Van Hertem, "Non-unit protection of HVDC grids with inductive dc cable termination," IEEE Trans. Power Del., vol. 31, no. 2, pp. 820-828, Apr. 2016.

[11] J. Sneath and A. D. Rajapakse, "Fault detection and interruption in an earthed HVDC grid using ROCOV and hybrid DC breakers," IEEE Trans. Power Del., vol. 31, no. 3, pp. 973-981, June 2016.

[12] W. Leterme, S. Pirooz Azad, and D. Van Hertem, “A Local Backup Protection Algorithm for HVDC Grids," IEEE Trans. Power Del., vol. 31, no. 4, pp. 1767-1775, Aug. 2016.

[13] ABB High Voltage Products, "Application Guidelines Overvoltage Protection,” Feb. 2009.

[14] T. Jonsson, P. Lundberg, S. Maiti, and Y. Jiang-Häfner, "Converter Technologies and Functional Requirements for Reliable and Economical HVDC Grid Design," in Cigré 2013 Canada Conf., Calgary, Alberta, Canada, 911 Sept. 2013, 9 pages. 